\subsection{Hiệu quả trong điêu trị:}

- Giảm các triệu chứng khó chịu của hội chứng cai, giảm số lần và mức độ thèm muốn hút thuốc, giảm các triệu chứng ho, đau rát họng sau 30 ngày điều trị

- Giảm nồng độ CO trong hơi thở từ $16.74 \pm$ 3.41(ppm) xuống còn 7.72 $33.66(\mathrm{ppm})(\mathrm{p}<0,05)$.

- Hiệu quả cai nghiện thuốc lá của trà nhúng BTL theo nồng độ $\mathrm{CO}$ trong hơi thở đạt tỷ lệ $38 \%$ tốt, $25 \%$ khá và $37 \%$ không kết quả.

- Hiệu quả cải thiện các triệu chứng của hội chứng cai theo thang điểm MPSS đạt tỷ lệ $31.0 \%$ tốt, $43.5 \%$ khá, $22.0 \%$ trung bình và $3.5 \%$ kém.

\subsection{Tác dụng không mong muốn}

- Trà nhúng BTL không làm thay đổi nhịp tim, huyết áp và các chỉ số xét nghiệm máu, sinh hóa máu, nước tiểu trước và sau khi điều trị.

- Trong quá trình nghiên cứu, không xuất hiện tác dụng không mong muốn nào của phương pháp can thiệp trên lâm sàng, cho thây đây là phương pháp an toàn cho bệnh nhân.

\section{TÀI LIÊU THAM KHẢO}

1. Bộ Y Tế, WHO (2015). Điều tra toàn câu về hút thuốc lá ở người trưởng thành tai Viêt Nam (Global Adult Tobacco survey - GATS).

2. Lương Ngọc Khuê (2015). Hướng dẫn xây dựng cơ sở y tế không khói thuốc lá, Nhà xuất bản Y học Hà Nội.

3. Vũ Văn Giáp, Nguyễn Hải Anh, Phan Thanh Thủy (2015). Kiến thức, thái độ và hành vi về thuốc lá, thuốc lào của bệnh nhân tại Trung tâm Hô hấp Bệnh viện Bạch Mai. Tạp chí Y học Việt Nam, tháng 2, $149-153$.

4. Văn Thi Thu Hà (2018), "Nghiên cứu tính an toàn trên thực nghiệm cưa viên CTL và tác dụng lâm sàng kểt hợp tư vấn trong điều tri nghiên thuốc lá", Luận văn Thạc sĩ Y học, Đại học Y Hà Nội.

5. U.S. Department of Health and Human Services (2014). The health consequences of smoking - 50 years of progress: A report of the Surgeon General. Atlanta: U.S Department of Health and Human Services, Centers for Disease Control and Prevention, National Center for Chronic Disease Prevention and Health Promotion, Office on Smoking and Health.

6. WHO (2007). The European tobacco control report.

\title{
CÁC THUộC TÍNH CỦA MUỐI THẢO DƯợC NGÂM CHÂN ĐÁP ỨNG KỲ VỌNG CỦA NGƯỜI SỬ DƯNG TAI THÀNH PHỐ HỒ CHÍ MINH: MộT NGHIÊN CỨU MỐ TẢ CẮT NGANG
}

\author{
Lê Đặng Tú Nguyên ${ }^{1}$, Đặng Thị Kiều Nga ${ }^{1}$, Trần Thị Hồng Nguyên ${ }^{1}$,
} Lê Thị Trang1, Đặng Lưu Việt Quý1, Thái Tú Minh Phương1, Võ Quang Huy ${ }^{1}$, Ngô Thị Hồng Uyên ${ }^{2}$, Lê Minh Quân ${ }^{1 *}$

\section{TÓM TẮT}

Mục tiêu: Khảo sát các thuộc tính mong đợi của người sử dụng sản phẩm muối thảo dược ngâm chân và đánh giá sự hài lòng của người sử dựng đối với sản phẩm thứ nghiệm tại TPHCM. Đối tượng và phương pháp: Nghiên cứu mô tả cắt ngang, khảo sát các thuộc tính của muối thảo dược trên 512 người sử dụng và sự hài lòng của 300 người sau 30 ngày sử dụng. Kết quả: Các thuộc tính được người sử dụng kỳ vọng ở sản phẩm muối thảo dược ngâm chân được đưa vào sản phẩm thử nghiệm là màu nâu $(21,88 \%)$; mùi sả chanh $(19,53 \%)$; đóng gói đơn liều, trong hộp giấy và chứa nhiêu túi zipper nhỏ $(57,81 \%)$; giá thành từ $100.000-150.000$ VND cho liêu trình sứ dung 30 ngày $(51.76 \%)$; nhiệt độ nước ngâm chân là $30-38^{\circ} \mathrm{C}$ $(65,23 \%)$, khoảng thời gian ngâm chân phù hợp là 20

\footnotetext{
${ }^{1}$ Đai học Y Dược thành phố Hồ Chí Minh

${ }^{2}$ Trường Đai hoc Kỹ thuât Y-Dước Đà Nã̃ng

Chịu trách nhiệm chính: Lê Minh Quân

Email: leminhquan@ump.edu.vn

Ngày nhận bài: 10.9.2021

Ngày phản biên khoa hoc: 8.11 .2021

Ngày duyệt bài: 15.11.2021
}

phút $(53,32 \%)$. Sản phẩm thử nghiệm đã đáp ứng được nhu câuu của người sử dụng về các thuộc tính cơ bản của môt sản phẩm muối thảo dước ngâm chân với mức độ hài lòng ở mức "Rất hài lòng" (4-5 điểm). Kết luân: Kết quả khảo sát người sử dụng về các thuộc tính cơ bản của sản phẩm muối thảo dược ngân châm thử nghiệm sẽ là tiền đề cơ bản, góp phần hoàn thiện chế phẩm trước khi thương mại hóa một cách hiệu quả và đáp ứng được nhu cầu của người sử dụng.

Từ khóa: muối thảo dược, ngâm chân, thành phố Hồ Chí Minh

\section{SUMMARY \\ SURVEYING THE ATTRIBUTES OF HERBAL SALT FOR FOOT BATH MEETING CONSUMERS' EXPECTATIONS IN HO CHI MINH CITY \\ Objective: Survey the expected attributes of consumers in Ho Chi Minh City about herbal salt for foot bath and assess consumer satisfaction with the test products. Subjects and methods: A cross- sectional descriptive study surveying consumers' expected attributes and satisfaction for the test products. Results: The attributes expected by consumers in the herbal salt for foot bath included in the test product were brown $(21.88 \%)$; smell of}


lemongrass (19.53\%); packed in single dose, in paper box and containing many small zipper bags ( $57.81 \%)$; price from 100,000 to 150,000 VND for a 30-day course of use $(51.76 \%)$; foot bath water temperature is $30-38^{\circ} \mathrm{C}(65.23 \%)$, suitable foot bath time is 20 minutes (53.32\%). The test product met consumer demand for the basic attributes of an herbal salt for foot bath with a satisfaction rating of "Very Satisfied" (4-5 points). Conclusion: The results of the consumer survey on the basic attributes of the test herbal salt for foot bath will be the basic premise, contributing to the completion of the preparation before commercialization effectively and satisfying the needs of consumers.

Keywords; herbal salt, foot bath, Ho Chi Minh city

\section{I. ĐăT VẤN ĐỀ}

Với sự phát triển không ngừng của nền kinh tế, thu nhậ̣p và mức sống của người dân cũng được gia tăng đáng kể. Chính vì vậy nhu cầu chắm sóc sức khỏe, làm đẹp ngày càng được quan tâm. Hiện nay, các sản phẩm như thực phẩm chức năng được sử dụng rộng rãi và được người sử dụng ưa chuộng trong lînh vực tăng cường, bảo vệ sức khỏe cũng như cải thiên đời sống tinh thần. Đặc biệt là những sản phẩm có nguồn gốc từ dược liệu, thiên nhiên đã được chứng nhận là có tác dụng hỗ trợ cho các bệnh lý, từ đó cải thiện tình trạng bệnh lý.

Thành phố Hồ Chí Minh là một trong những trung tâm lớn về kinh tế, các lînh vực phát triển về công nghiệp và nông nghiệp cũng đang được chú trọng. Trong cơ cẫu các ngành kinh tế, khu vực dịch vụ chiếm tỷ trọng từ $58,16 \%$ - 60,07\%, khu vực cônng nghiệp - xây dựng chiếm tỳ trọng từ $39,19-41,07 \%$ và nông nghiệp chiếm tỳ trọng từ $0,74 \%-0,78 \%$. Riêng đồi với huyện Cần Giờ có thế mạnh về vị trí địa lý và hiện đang được đầu tư phát triển trong ngành nghề sản xuất muối. Theo nghiên cứu của tác giả Ngô Thị Phương Lan, huyện Cần Giờ cần giải quyết vấn đề đâu ra cho sản lượng muối sản xuất bằng việc đa dạng hóa chưng loại sản phẩm nhằm nầng cao thu nhập của diêm dân, qua đó góp phần bảo tồn và phát triển ngành nghề truyền thống của địa phương [1].

Trên thị trường, ngoài các sản phẩm muối dùng trong bảo quản - chế biến thực phẩm (muối iod, muối sẫy, muối hột) hoặc dùng trong công nghiệp, muỗi còn có thể được dùng trong các chể phẩm hố trợ sức khỏe, điển hình là dòng sản phẩm muối thảo dược dùng để ngâm chân. Tuy nhiên, các chế phẩm đã được thương mại hóa trên thị trường cũng có một số hạn chể nhẩt định: nguồn gốc xuất xứ của thành phần công thức không rỗ ràng, chế phẩm đóng gói đa liêu dẫn đến sự bất tiện trong sử dụng... Do đó, nghiên cứu mục tiêu chính: (i) Khảo sát các thuộc tính mong đợi của người sử dụng trên địa bàn TPHCM về sản phẩm muối thảo dược ngâm chân; (ii) Đánh giá sự hài lòng của người sử dụng đối với sản phẩm thử nghiệm.

\section{II. ĐỐI TƯỢNG VÀ PHƯƠNG PHÁP NGHIÊN CỨU}

2.1. Đối tượng nghiên cứu. Người sử dụng tại Thành phố Hồ Chí Minh

Tiêu chí lựa chọn: Đồng ý tham gia khảo sát; đã từng sử dụng sản phẩm hoặc biết về sản phẩm muối thảo dược ngâm chân; Tự quyết định việc sử dụng sản phẩm.

Tiêu chí loại trừ: Chưa từng sử dụng sản phẩm hoặc không biết về sản phẩm muối thảo dược ngâm chân; Không tự ý quyết định sử dụng sản phẩm.

\subsection{Phương pháp nghiên cứu}

2.2.1. Thiết kế nghiên cứu: Nghiên cứu mô tả cắt ngang.

2.2.2. Thời gian và địa điểm: Nghiên cứu được tiến hành từ tháng 3 đến tháng 6 năm 2021 tại thành phố Hồ Chí Minh

2.2.3. Cỡ mẫu và phương pháp chọn mẫu: Tiến hành nghiên cứu ban đầu trên 512 đối tượng là người sử dụng trên địa bàn TPHCM để khảo sát về các thuộc tính mong đợi của sản phẩm muối thảo dược ngâm chân. Sau 30 ngày khảo sát ban đầu, số người sử dụng đủ điều kiện tham gia nghiên cứu là 300 người. Xác suất không mắc sai số loại II (Type II error) 80\% là 300 người sử dụng.

Phương pháp chọn mẫu thuận tiện với những người sử dụng sản phẩm muỗi thảo dược và mời tham gia nghiên cứu.

2.2.4. Nội dung nghiên cứu. Nghiên cứu tiến hành khảo sát người sử dụng thông qua 2 giai đoạn với 2 bộ câu hỏi khảo sát riêng biệt:

Giai đoạn 1: Khảo sát các thuộc tính mong đợi của người sử dụng trên địa bàn TPHCM về sản phẩm muối thảo dược ngâm chân:

Bộ câu hỏi khảo sát được xây dựng dựa trên tổng quan tài liệu về các thuộc tính và mức độ thuộc tính cho sản phẩm, bao gồm 2 nội dung: (i) phần thông tin khách hàng; (ii) phần khảo sát về các thuộc tính kỳ vọng của khách hàng đối với sản phẩm gồm 3 nhóm thuộc tính chính là thuộc tính kỹ thuật, thuộc tính khách hàng và thuộc tính thị trường [2].

Giai đoạn 2: Đánh giá sự hài lòng của người sử dụng đổi với sản phẩm thử nghiệm.

Bộ câu hỏi khảo sát được xây dựng dựa trên ý kiển các chuyên gia về việc đánh giá mức độ yêu thích của người sử dụng sau khi sử dụng thử 
nghiệm sản phẩm, bao gồm 2 nội dung: (i) phần thông tin khách hàng; (ii) Sự hài lòng của sản phẩm muối ngâm chân thảo dược được thiết lập dựa trên 3 nhóm thuộc tính chính của 1 sản phẩm thuộc tính tìm kiếm (search attribute), thuộc tính trải nghiệm (experience attribute), thuộc tính tín nhiệm (credence attribute) [3],[4],[5].

\subsubsection{Các bước tiến hành:}

Giai đoạn 1: Khảo sát các thuộc tính mong đợi của người sử dụng trên địa bàn TPHCM về sản phẩm muối thảo dược ngâm chân

\section{Các bước tiến hành:}

Bước 1: Xây dựng các thuộc tính sơ bộ của sản phẩm dựa trên cơ sở lý thuyết

Bước 2: Khảo sát sơ bộ với 30 chuyên gia nhằm xác định được các thuộc tính và mức thuộc tính sơ bộ của sản phẩm muối thảo dược ngâm chân

Bước 3: Khảo sát các thuộc tính mong đợi của người sử dụng trên địa bàn TPHCM về sản phẩm muối thảo dược ngâm chân. Khảo sát được thực hiện dựa trên phiếu khảo sát ở cả 2 phương thức là online và offline.

Bước 4: Tính tỷ lệ lựa chọn cho các mức độ thuộc tính để tìm ra các mức độ thuộc tính được người sử dụng yêu thích hơn nhằm thiết kế các thuộc tính của sản phẩm thử nghiệm phù hợp với kỳ vọng của khách hàng.

Giai đoạn 2: Đánh giá sự hài lòng của người sử dụng đổi với sản phẩm thử nghiệm

Sau khi hoàn thành mục tiêu 1 , nhóm nghiên cứu đã thiết kễ sản phẩm thử nghiệm với các đặc tính phù hợp. Nội dung nghiên cứu này được thực hiện nhằm hoàn thiện chế phẩm trước khi thương mại hóa, không nhằm mục tiêu thử nghiệm lâm sàng. Khảo sát này thực hiện đơn thuần về mặt thị trường, các chỉ tiêu được đánh giá chỉ là thuộc tính vật lý của sản phẩm mà không quan tâm đến đặc tính trị liệu. Do vậy, nội dung nghiên cứu này không chịu sự chi phối của các quy định về y đức.

Các bước tiến hành: Bước 1: Khảo sát được tiến hành với cỡ mẫu là 300 người sử dụng dùng. Người sử dụng được sử dụng trong vòng 30 ngày (tương đương với 1 tháng), nghiên cứu sẽ tiến hành ghi nhận phản hồi của người sử dụng 03 lần trong vòng 30 ngày sử dụng (tương ứng với phỏng vấn lập lại cứ mỗi 10 ngày một lần trong quá trình sử dụng sản phẩm).

Bước 2: Thu phiếu khảo sát và kiểm tra sự hợp lệ của phiếu khảo sát.

Bước 3: Phân tích sự hài lòng của người sử dụng sản phẩm:

Mức độ hài lòng được đánh giá dựa trên thang đo Likert với quy ước:

\begin{tabular}{|c|c|c|c|c|c|}
\hline Điếm & $\mathbf{0 - 1}$ & $\mathbf{1 - 2}$ & $\mathbf{2 - 3}$ & $\mathbf{3 - 4}$ & $\mathbf{4 - 5}$ \\
\hline Ý nghĩa & $\begin{array}{c}\text { Hoàn toàn } \\
\text { không hài lòng }\end{array}$ & $\begin{array}{c}\text { Không hài } \\
\text { lòng }\end{array}$ & $\begin{array}{c}\text { Không ý kiến/ } \\
\text { Trung lập }\end{array}$ & Hài lòng & Rất hài lòng \\
\hline
\end{tabular}

2.2.6. Phương pháp xử lý số liệu. Sử dụng các phương pháp thống kê cơ bản để trình bày kết quả. Giá trị trung bình về mức độ hài lòng được tính toán với từng thuộc tính. Sử dụng kiểm định thống kê ANOVA với mức ý nghĩa $\mathrm{p}<0,001$ để xem xét sự khác biệt có ý nghĩa

thống kê của mức độ hài lòng về các thuộc tính qua 3 giai đoạn thực hiện đánh giá.

\section{KẾT QUẢ NGHIÊN CứU}

3.1. Các thuộc tính mong đợi của người sử dụng trên địa bàn TPHCM về sản phẩm muối thảo dược ngâm chân

Bảng 1. Kêt quả khảo sát về các thuộc tính mong đợi của người sử dụng trên địa bàn TPHCM về sản phẩm muôi thảo dước ngâm chân

\begin{tabular}{|c|c|c|c|}
\hline Thuộc tính & Mức độ thuộc tính & Tân số $(n=512)$ & Tỉ lệ \% \\
\hline \multirow{4}{*}{$\begin{array}{l}\text { Màu của } \\
\text { sản phẩm }\end{array}$} & Vàng & 114 & $22,27 \%$ \\
\hline & Hồng & 122 & $23,83 \%$ \\
\hline & Nâu & 112 & $21,88 \%$ \\
\hline & Khác & 164 & $32,03 \%$ \\
\hline \multirow{7}{*}{$\begin{array}{l}\text { Mùi sản } \\
\text { phẩm }\end{array}$} & Sả chanh & 100 & $19,53 \%$ \\
\hline & Gừng & 44 & $8,59 \%$ \\
\hline & Quế & 58 & $11,33 \%$ \\
\hline & Hượng tháo & 68 & $13,28 \%$ \\
\hline & Bưởi & 55 & $10,74 \%$ \\
\hline & Bạc hà & 71 & $13,87 \%$ \\
\hline & Khác & 116 & $22,66 \%$ \\
\hline \multicolumn{4}{|c|}{ Qui cách đóng gói } \\
\hline Qui cách & Đơn liều & 296 & $57,81 \%$ \\
\hline
\end{tabular}


TẠP CHÍ Y HỌC VIẸT NAM TẬP 509 - THÁNG 12 - SÓ 2 - 2021

\begin{tabular}{|c|c|c|c|c|}
\hline & \multicolumn{2}{|r|}{ Đa liều } & 137 & $26,76 \%$ \\
\hline & & Cả 2 qui cách & 79 & $15,43 \%$ \\
\hline \multirow{6}{*}{ Đơn liều } & \multirow{3}{*}{$\begin{array}{l}\text { Sản phẩm } \\
\text { chứa trong }\end{array}$} & Hộp giấy chứ nhiều túi zipper nhỏ & 177 & $34,57 \%$ \\
\hline & & Hộp giấy chứa nhiều túi polymer nhỏ & 59 & $11,52 \%$ \\
\hline & & Hộp giấy chứa nhiều ví xé & 139 & $27,15 \%$ \\
\hline & \multirow{3}{*}{ Số lượng viên } & 10 viên & 132 & $25,78 \%$ \\
\hline & & 20 viên & 128 & $25,00 \%$ \\
\hline & & 30 viên & 91 & $17,77 \%$ \\
\hline \multirow{6}{*}{ Đa liều } & \multirow{2}{*}{$\begin{array}{l}\text { Sản phẩm } \\
\text { chứa trong }\end{array}$} & Chai nhựa có nắp & 88 & $17,19 \%$ \\
\hline & & Hộp giấy chứa chai nhựa có nắp & 125 & $24,41 \%$ \\
\hline & \multirow{4}{*}{$\begin{array}{l}\text { Dung tích } \\
\text { chai nhựa }\end{array}$} & $250 \mathrm{ml}$ & 52 & $10,16 \%$ \\
\hline & & $500 \mathrm{ml}$ & 121 & $23,63 \%$ \\
\hline & & $750 \mathrm{ml}$ & 22 & $4,30 \%$ \\
\hline & & $1000 \mathrm{ml}$ & 18 & $3,52 \%$ \\
\hline \multicolumn{5}{|c|}{ Chương trình khuyến mãi và cách tiếp cận thông tin } \\
\hline \multirow{3}{*}{$\begin{array}{l}\text { Tư vấn sản } \\
\text { phẩm }\end{array}$} & Trực & tiếp từ nhân viên bán hàng & 104 & $20,31 \%$ \\
\hline & Trực tiếp từ & hân viên bán hàng có chuyên môn & 240 & $46,88 \%$ \\
\hline & Thố & g tin quảng cáo sản phẩm & 168 & $32,81 \%$ \\
\hline \multirow{4}{*}{$\begin{array}{l}\text { Tìm kiếm } \\
\text { sản phẩm }\end{array}$} & & Internet & 315 & $61,52 \%$ \\
\hline & & Nhà thuốc & 124 & $24,22 \%$ \\
\hline & & Spa & 42 & $8,20 \%$ \\
\hline & & enh viện Y học cố truyền & 31 & $6,05 \%$ \\
\hline \multirow{2}{*}{$\begin{array}{l}\text { Chương trình } \\
\text { khuyên mãi }\end{array}$} & & Tặng kèm sản phấm & 316 & $61,72 \%$ \\
\hline & & ảm giá khi mua số lượng & 196 & $38,28 \%$ \\
\hline \multicolumn{5}{|c|}{ Giá sản phấm } \\
\hline \multirow{3}{*}{$\begin{array}{c}\text { Ánh hưởng } \\
\text { của giá }\end{array}$} & & á ảnh hưởng đến QĐMH & 139 & $27,15 \%$ \\
\hline & Giá k & רông ảnh hưởng đến QĐMH & 31 & $6,05 \%$ \\
\hline & Giá và C & ất lượng ảnh hưởng đến QĐMH & 342 & $66,80 \%$ \\
\hline \multirow{3}{*}{$\begin{array}{l}\text { Giá sản } \\
\text { phẩm }\end{array}$} & & $50.000-100.000$ VND & 143 & $27,93 \%$ \\
\hline & & $00.000-150.000 \mathrm{VND}$ & 265 & $51,76 \%$ \\
\hline & & $50.000-200.000$ VND & 104 & $20,31 \%$ \\
\hline \multicolumn{5}{|c|}{ Thông tin khi dùng sản phẩm } \\
\hline \multirow{2}{*}{$\begin{array}{l}\text { Nhiêt độ của } \\
\text { nước khi pha }\end{array}$} & & Nước ấm 30-38 & 334 & $65,23 \%$ \\
\hline & & Nước ấm 38-45 & 178 & $34,77 \%$ \\
\hline \multirow{3}{*}{$\begin{array}{l}\text { Thời gian } \\
\text { ngâm chân }\end{array}$} & & Khoảng 10 phút & 190 & $37,11 \%$ \\
\hline & & Khoảng 20 phút & 273 & $53,32 \%$ \\
\hline & & Khoảng 30 phút & 49 & $9,57 \%$ \\
\hline \multirow{4}{*}{$\begin{array}{c}\text { Màu sản } \\
\text { phẩm khi } \\
\text { pha với } \\
\text { nước }\end{array}$} & & Vàng & 183 & $35,74 \%$ \\
\hline & & Hồng & 210 & $41,02 \%$ \\
\hline & & Nâu & 115 & $22,46 \%$ \\
\hline & & Khác & 4 & $0,78 \%$ \\
\hline
\end{tabular}

Có thể thấy, đặc điểm của mẫu khảo sát chủ yếu ở độ tuối $20-50$ tuổi $(>80 \%)$, thu nhập dưới 9 triệu đồng $(75,39 \%)$, trình độ trung cấp, cao đẳng và đại học $(87,5 \%)$. Trên tổng số người khảo sát có $8,2 \%$ đã sử dụng sản phẩm muối thảo dược ngâm chân; $37,11 \%$ biết về sản phẩm và $19,34 \%$ có nhu câu sử dụng sản phẩm. Kết quả khảo sát được trình bày trong Bảng 1 .

3.2. Sự hài lòng của người tiêu đối với sản phẩm thử nghiệm sau khi sử dụng $\mathbf{3 0}$ ngày

Bảng 2. Kêt quả khảo sát về sự hài lòng của người tiêu đôî với sản phẩm thử nghiệm sau khi sử dung 30 ngày $(n=300)$

\begin{tabular}{|c|c|c|c|c|}
\hline \multirow{2}{*}{ Thuộc tính } & \multicolumn{3}{|c|}{ Mức độ hài lòng [Mean (SD)] } & \multirow{2}{*}{ p-value } \\
\cline { 2 - 4 } & Giai đoạn 1 & Giai đoạn 2 & Giai đoạn 3 & \\
\hline Độ ốn định màu của sản phấm & $4,26(0,54)$ & $4,26(0,65)$ & $4,28(0,71)$ & 0,017 \\
\hline Độ ốn đinh mùi của sản phấm & $4,27(0,62)$ & $4,31(0,67)$ & $4,29(0,73)$ & 0,016 \\
\hline Sự tiện lợi của quy cách đóng gói đơnn liều & $4,50(0,58)$ & $4,55(0,65)$ & $4,51(0,68)$ & 0,012 \\
\hline Giá của sản phấm muối thảo dược ngâm & 4,49 & 4,47 & 4,49 & 0,012 \\
\hline
\end{tabular}




\begin{tabular}{|c|c|c|c|c|}
\hline $\begin{array}{c}\text { chân cho liệu trình sử dụng } 10 \text { ngày là } \\
\text { 35.000-50.000VND }\end{array}$ & $(0,60)$ & $(0,68)$ & $(0,71)$ & \\
\hline Nhiệt độ nước khi ngâm chân là $38-42^{\circ} \mathrm{C}$ & $4,41(0,56)$ & $4,36(0,64)$ & $4,40(0,64)$ & 0,014 \\
\hline Thời gian ngâm chân là 20 phút & $4,34(0,67)$ & $4,39(0,63)$ & $4,40(0,66)$ & 0,014 \\
\hline Màu của nước khi pha với muối thảo dược & $4,26(0,67)$ & $4,27(0,71)$ & $4,30(0,73)$ & 0,017 \\
\hline Mức độ hài lòng về việc làm sạch vùng & 4,36 & 4,43 & 4,40 & 0,014 \\
chân sau khi ngâm chân & $(0,63)$ & $(0,66)$ & $(0,74)$ & \\
\hline
\end{tabular}

*Ghi chú: Giai đoạn 1: 10 ngày đâu, Giai đoạn 2: 10 ngày tiếp theo, Giai đoạn 3: 10 ngày cuối

Từ kết quả khảo sát, ghi nhận mức độ hài lòng của người sử dụng đối với các thuộc tính của sản phẩm đều ở mức "Rất hài lòng" (4-5 điểm) và không có sự khác biệt có ý nghĩa thổng kê về điểm trung bình mức độ hài lòng của người sử dụng qua 3 giai đoạn khảo sát.

\section{BÀN LUÂ̂N}

4.1. Các thuộc tính mong đợi của người sử dụng trên địa bàn TPHCM về sản phẩm muối thảo dược ngâm chân. Từ cơ sở lý thuyết, 6 thuộc tính sơ bộ của sản phẩm được tổng hợp là: màu sắc sản phẩm, mùi sản phẩm, qui cách đóng gói, chương trình khuyến mãi và cách tiếp cận thông tin, giá sản phẩm, thông tin khi dùng sản phẩm. Nghiên cứu đã tiến hành khảo sát trên 30 chuyên gia bao gồm 17 dược sĩ làm việc tại nhà thuốc, 6 bác sĩ y học cổ truyền, 4 y sĩ y học cổ truyền làm việc trong bệnh viện, 3 nhân viên đang làm việc tại spa. Từ đó, ghi nhận các thuộc tính và mức độ thuộc tính của muối thảo dược ngâm chân.

Từ kết quả khảo sát, nghiên cứu ghi nhận các thuộc tính được người sử dụng kỳ vọng ở sản phẩm muối thảo dược ngâm chân như sau:

(1) Màu sắc: không có sự khác biệt rõ rệt giữa tỷ lệ lựa chọn giữa màu hồng $(23,83 \%)$, vàng $(22,27 \%)$, nâu $(21,88 \%)$. Vì chế phẩm muối thảo dược ngâm chân được điều chế bằng cách phối trôn cao dược liêu với muối, nên sẽ chọn màu nâu là màu của cao dược liệu nhằm mục đích giúp người sử dụng dễ dàng rửa và vệ sinh lại khi ngâm chân.

(2) Mùi sản phẩm: mùi sả chanh (19,53\%).

(3) Quy cách đóng gói: đóng gói đơn liêu, trong hộp giây và chứa nhiều túi zipper nhỏ $(57,81 \%)$.

(4) Giá sản phẩm: khoảng từ 100.000 150.000 VND cho liệu trình sử dụng 30 ngày chiếm tỉ lệ cao nhất $(51,76 \%)$. Nghiên cứu thực hiện phép kiểm chi bình phương để xem xét mỗi quan hệ giữa việc lựa chọn giá sản phẩm và thu nhập người sử dụng. Kêt quả cho thấy với nhóm người sử dụng có thu nhập càng cao thì quyết định lựa chọn giá của sản phẩm càng cao $(\mathrm{p}<0,001)$. Đồng thời, $66,8 \%$ người khảo sát lựa chọn giá và chất lượng ảnh hưởng đến quyết định mua hàng.

(5) Chương trình khuyến mãi và cách tiếp cận thông tin: $61,72 \%$ đối tượng tham gia nghiên cứu lựa chọn hình thức khuyến mãi là tặng kèm sản phẩm và đa số người sử dụng lựa chọn được tư vấn sản phẩm từ nhân viên bán hàng có chuyên môn $(46,88 \%)$ và tìm kiếm sản phẩm trên Internet $(61,52 \%)$. Điều này tương tự với nhận định của các chuyên gia ở bước khảo sát sơ bộ.

(6) Thông tin khi tiêu dùng sản phẩm: nhiêt độ nước ngâm chân ưa thích của phân đông đối tượng được khảo sát là $30-38^{\circ} \mathrm{C}(65,23 \%)$, khoảng thời gian ngâm chân phù hợp là 20 phút $(53,32 \%)$.

4.2. Sự hài lòng của người sử dụng đối với sản phẩm thử nghiệm sau khi sử dụng 30 ngày. Dựa trên kết quả khảo sát trên, nhóm nghiên cứu đã tiến hành thiết kế sản phẩm thử nghiệm bao gồm các thuộc tính: màu nâu, hương sả chanh, qui cách đóng gói đơn liều, giá sản phẩm 100.000 - 150.000 VND cho liêu trình sử dụng 30 ngày. Đồng thời, khi thực hiện khảo sát, người sử dụng được hướng dấn ngâm chân ở nhiệt độ $38-42^{\circ} \mathrm{C}$, thời gian ngâm chân 20 phút. Kết quả khảo sát về sự hài lòng của 300 người sử dụng khi trải nghiệm sản phẩm qua 30 ngày được trình bày ở Bảng 2.

Từ kết quả khảo sát, ghi nhân mức độ hài lòng của người sử dụng đối với các thuộc tính của sản phẩm đều ở mức "Rất hài lòng" (4-5 điểm) và không có sự khác biệt mang ý nghĩa thống kê về điểm trung bình mức độ hài lòng của người sử dụng qua 3 giai đoạn khảo sát. Vì vậy, có thể kết luận sản phẩm thử nghiệm sẽ có thể đáp ứng được nhu cầu của phần đông người sử dụng trên tiều chí các thuộc tính cơ bản của một sản phẩm muối thảo dược ngâm chân.

\section{KẾT LUÂN}

Nghiên cứu đã tiến hành khảo sát và xác định được các thuộc tính kỳ vọng của người sử dụng tại TPHCM về sản phẩm thảo dược ngâm chân về màu sắc, mùi vị, quy cách đóng gói, giá, chương trình khuyến mãi - tư vấn và thông tin sử dụng sản phẩm. Dựa vào các thuộc tính trên, 
nghiên cứu tiến hành thiết kế sản phẩm thử nghiệm và ghi nhận được mức độ hài lòng của người sử dụng sau khi sử dụng 30 ngày với mức đánh giá là rất hài lòng. Đây sẽ là cơ sở quan trọng giúp đánh giá sản phẩm về mặt thị trường và góp phần hoàn thiện chế phẩm trước khi thương mại hóa một cách hiệu quả và đáp ứng được kỳ vọng của người sử dụng.

\section{Lờ' CẢM ƠN}

Nghiên cứu này được tài trợ bởi Sở Khoa Học và Công nghệ Thành phố Hồ Chí Minh (DOST HCMC) cho ThS Lê Đặng Tú Nguyên).

TÀI LIỆU THAM KHẢO

1. Lan Ngô T. P., "Các dạng thức sinh kế của cư dân huyện Cần Giờ, Thành phố Hồ Chí Minh: sự tương tác của yếu tố chính sách, thị trường và môi trường", Tapp chí phát triển KH\&CNं, 2016, 10 (3).

2. Earle M. and Earle R., "Creating new foods", The product developer's guide, Chadwick House group Itd, UK. 2009, pp. 1-192.

3. Ford G. T., Smith D. B., Swasy J. L., "An empirical test of the search, experience and credence attributes framework", ACR North American Advances. 1988.

4. Arora R., "Product positioning based on search, experience and credence attributes using conjoint analysis", Joumal of Product \& Brand Management, 2006.

5. Girard T., Dion P., "Validating the search, experience, and credence product classification framework", Journal of Business Research. 2010, $63(9-10), 1079-1087$.

\section{THỰC TRANG SÀNG LỌC TIỀN SẢN GIÂT, SẢN GIÂTT Ở NHÓM Có YẾU TỐ NGUY Cơ VÀ MộT Số YẾU TỐ LIỂN QUAN TẠI BỆNH VIỆN PHỤ SẢN HẢI PHÒNG}

\section{TÓM TẮT}

Tiền sản giât là một bệnh lí phức tạp thường xảy ra trong ba tháng cuối của thời kì mang thai và có thể gây ra những tác hại nguy hiểm đến tính mạng của người mẹ và thai nhi. Mục tiêu: Đánh giá thực trạng sàng lọc tiền sản giật, sản giật ở nhóm có yếu tố nguy cơ và một số yếu tố liên quan tại Bệnh viện Phụ Sản Hải Phòng. Đối tượng và phương pháp nghiến cứu: Thai phụ nằm trong nhóm đối tượng nguy cơ bị tiền sản giật có khám, quản lý và kết thúc thai kỳ tại Bệnh viện Phụ Sản Hải Phòng tữ tháng 7/2019 đến tháng 9/2020. Kết quả: từ 07/2019 đến 9/2020 có 476 trường hợp có yếu tố nguy cơ tiền sản giật, sản giật: 306 trường hợp không theo dõi, sàng lọc trong quá trình mang thai chiếm $64,3 \%$ và 170 trường hợp sàng lọc, theo dõi và tuân thủ điều trị chiếm $35,7 \%$. Kết cục thai kì có 3 trường hợp bị tiền sản giật chiếm $1,8 \%$. Ở nhóm tuổi trên 40 có $16,7 \%$ là bị tiền sản giật, nhóm tuổi dưới 40 tỉ lệ tiền sản giật là $1,2 \%$. Có mối liên quan giữa bệnh lý nội khoa với tiền sản giật $p<0,01$. Kết luận: chỉ có $35,7 \%$ thai phụ có yếu tố nguy cơ tiền sản giật tham gia sàng loc, theo dõi, điêu trị. Có mối liên quan giữa bệnh lý nội khoa với tiền sản giật.

Tư khóa: sàng lọc, tiền sản giật, sản giật

\section{SUMMARY}

\section{SITUATION OF PRE-ECLAMPSIA, ECLAMPSIA SCREENING IN RISK GROUP}

*Bênh viên Phu sản Hải Phòng

Chịu trách nhiệm chính: Vũ Văn Tâm

Email: Drvuvantam@gmail.com

Ngày nhận bài: 13.9.2021

Ngày phản biện khoa học: 9.11.2021

Ngày duyệt bài: 15.11.2021

\section{Vũ Văn Tâm*, Lưu Vũ Dũng*}

\section{AND SOME REALATED FACTORS AT HAI PHONG OF OBSSTETRICS AND GYNECOLOGY HOSPITAL}

Pre-eclampsia is a complex condition that might occours during the third trimester of pregnancy and can have life-threatening consequences for the mother and fetus. Purpose: assess the status of preeclampsia, eclampsia screening in risk group and some related factors at $\mathrm{Hai}$ Phong Obstetrics and Gynecology Hospital. Subjects and methods: Pregnant women in the risk group for pre-eclampsia were examined, managned and terminated at the Hai Phong Obstetrics and Gynecology Hospital (7/2019-9/2020). Cross-sectional study. Results: of 474 caces with risk factor of pre-eclampsia, eclampsia, 306 cases were not monitored, screened, followed treatment $(64,3 \%)$ and 170 cases were monitored, screened and followed treatment during pregnancy $(35,7 \%)$. There are 3 cases with pre-eclampsia, accouting for $1,8 \%$. There are $16,7 \%$ patients with age more than 40 years old who were diagnosied pre-eclampsia, the age group less than 40 has pre-eclampsia with $1,2 \%$. There is a relationship between medical condition and preeclampsia with $p<0,01$. Conclusion: there is $35,7 \%$ pregnant women with pre-ecalpmsia risk factor when they are monitored, screened, followed treatment during pregnancy. There is a relationship between medical condition and pre-eclampsia with $\mathrm{p}<0,01$.

Keywords; screening, pre-eclampsia, eclampsia.

\section{I. ĐẠTT VẤN ĐỀ}

Tiền sản giật là một bệnh lí phức tạp thường xảy ra trong ba tháng cuối của thời kì mang thai và có thể gây ra những tác hại nguy hiểm đến tính mạng của người mẹ và thai nhi. Hàng năm 